\title{
Technology in Healthcare: Differing Points of View
}

Heidi Deagle, BA, BSN, RN, MA

Clinical Instructor and

Academic Advisor

Bachelor of Science

in Nursing Program

North Island College

Comox Valley, BC

I arrive to your Unit full of fear and apprehension. Your face is friendly though, and your smile sincere, so I will try to let you help me (I hope you can help me).

I sit on the neatly made bed in this unwelcoming room you are already calling "mine." Nothing human here. Not even the blanket looks warm.

I try to relax, but there is nothing here to comfort me. I cannot understand what these buttons and switches do. I am afraid to touch things I do not understand, so I sit in the dark.

I wait for instruction, for companionship, for answers; I wait for healing.

In time, you come to see me, and you are not alone.

There is another being with you; we are not introduced. I am not certain about what it does - will I be measured or tested or scanned? Will it hurt?

Then I see it is only a mobile computer. That's not so bad, I guess.

Only, you do not sit with me. You stand and face the screen. I am still seated on the bed and cannot see what you see.

You ask me questions in your cheery way. One question after another, hardly any difference between them. "May I confirm your address? Who is your next of kin?

Do you identify as First Nations, Inuit or Métis? Can you rate your mood on a scale of 1 to 10 ? Do you smoke, drink or do drugs? Are you in pain?"

You are asking me some things that are hard to think about, much less talk about with a stranger. I want to trust you ... but I cannot see your eyes. They flicker up occasionally; otherwise you are staring at the screen, your fingers moving across the keyboard. I wonder, where you are putting my words, my story?

You must know what is best, but I have heard of people's secrets leaking out on the Internet. Who will see what I share with you? I don't know, so I don't tell you everything. Better safe than sorry.

If only you would sit with me, nothing between our human being; then I would tell you what you want to know because I know it would be stored in your heart, not in a machine. Annoyed, you say "Darn, the program seems to have lost connection and my screen went blank."

Perfect, I think; now maybe we can connect. 
You arrive to the Unit looking unsure of yourself. I approach you gently, sensing your nervousness. I think you will be pleased to see how modern and intuitive these new hospital rooms are.

I will show you all of the advanced features of your room: several ways to adjust the bed for your personal comfort, switches for bright lights, dim lights and window blinds, touchless taps and toilet and a locker you can set with a personal digital security code.

First, I leave you to get settled in.

I sign-on at the laptop cart and wheel it into your room. Typing notes in real time is such an advantage. Rather than being stuck behind the nursing station, trying to finish my charting with constant interruptions, I can get all the necessary information from you and complete the required documentation accurately and immediately; this gives me time to get to know you better.

We are fortunate to live in an era with these advances in technology and healthcare. The old way of doing things was so time-consuming and cumbersome.

The electronic health record is amazing! Patients and their families who won't have to explain the same things at every care encounter. Your story, your history - all you share with me today will be there instantly; everything the healthcare providers need to know about you, just a simple click away.

Technology will help us to provide a better quality of care and to have more time available for meaningful engagement with you. 